\title{
Evaluating Effect of Knowledge Management in Sales Forecasting: Evidence from Iran's Food Retail Industry
}

\author{
Ehsan Borousan (Corresponding author) \\ Faculty of Management, Multimedia University (MMU) \\ Jalan Multimedia 63100, Cyberjaya Selangor, Malaysia \\ Tel: 60-1-7238-3047 E-mail: ehsan_boroosan@yahoo.com
}

Navid Sharifian

Faculty of Management, Multimedia University (MMU)

Jalan Multimedia 63100, Cyberjaya Selangor, Malaysia

Tel: 60-1-7288-1906 E-mail: Navid_sharifian@yahoo.com

\author{
Azin Hajiabolhassani \\ Faculty of Management, Multimedia University (MMU) \\ Jalan Multimedia 63100, Cyberjaya Selangor, Malaysia \\ E-mail: azin_abolhassani@yahoo.com
}

Shiva Hazrati

Faculty of Management, Multimedia University (MMU)

Jalan Multimedia 63100, Cyberjaya Selangor, Malaysia

Tel: 60-1-7288-1540 E-mail: shiva_ha@yahoo.com

$\begin{array}{lcc}\text { Received: March 4, } 2011 \quad \text { Accepted: March 31, } 2011 \quad \text { Published: October 1, } 2011 \\ \text { doi:10.5539/ijbm.v6n10p213 } & \text { URL: http://dx.doi.org/10.5539/ijbm.v6n10p213 }\end{array}$

\begin{abstract}
The paper is going to look at forecasting in a new way, using knowledge management concepts. Any forecast including sales forecast have to use data, Information or knowledge in a personalized or codified way. Codified knowledge can be assumed as the result of knowledge management. In this research codified knowledge used for forecasting is measured in seven companies and also the accuracy of forecasting is evaluated. Results demonstrate a significant growth of accuracy by using codified knowledge which is an elementary implementation of knowledge management.
\end{abstract}

Keywords: Sales forecasting, Knowledge management, Codified knowledge, Iran food industry

\section{Introduction}

With the rapid and constant changes taking place in information technology and Internet, traditional business models have to continue meeting the changing business environment in order to survive in the market. Only firms which participate in the creation and utilization of knowledge can hope to have the rewards of business reform in today's knowledge-based economy. Therefore, both industries and academia have become interested in the issues surrounding knowledge management. On the other hand forecasting has become a necessity for the businesses to become lean and efficient. For managers, any effort to make forecasting more accurate is very important. Looking at two concepts of "Knowledge Management" and "Forecasting" it seems knowledge management can be a proper way to help forecasting be more accurate. Going through literature, it is obvious 
that using knowledge management in forecasting procedure has been neglected. Thus a deeper look at importance of using knowledge in forecasting procedure in firms is necessary.

\section{Forecasting}

\subsection{New product forecasting}

New product forecasting is an important subject. Yet, compared to the forecasting of ongoing product demand and sales, new product forecasting receives considerably less attention, especially when counting the number of publications on each respective topic. Those publications that discuss about the topic of new product forecasting mainly focus on statistically complicated techniques.

New product forecasting should not be viewed as mysterious. However, it certainly can be viewed as a complicated attempt due to its many challenges. One main challenge is overcoming the characteristically low credibility and low accuracy associated with new product forecasts. Benchmarking research finds that new product forecast accuracy on average one year after launch is slightly about 50 percent (Kahn 2002). Another major challenge is time management. When forecasting existing products, one can usually run a forecasting engine embedded within a company's production planning computer systems, but, in contrast, forecasting a new product requires more manual attention, and thus, considerable time resources. The ability to afford additional time to develop a new product forecast may be high-priced, particularly if a forecaster is responsible for a product mix of over ten thousand items. Less available time means less thinking on inherent new product forecasting issues like draw (the percent of new product's volume coming from products within a product category), cannibalization (the percent of a new product's volume coming from other company products), category growth (the percent of new product's volume coming from new category buyers who enter the category to purchase the new product), and category expansion (the percent of new product's volume coming from increased category consumption among current category buyers where the purchase of the new product is incremental volume for the buyers). While high accuracy is never certain and time is a limited resource, employing a systematic approach can "demystify" the new product forecasting endeavor and force attention to those new products and issues deserving of attention. Subsequently, attending to the right issues primarily can manifest more accurate new product forecasts and optimize one's time in generating this forecast.

\subsection{Sales forecasting}

A sales forecast is a prediction based on previous sales performance and an analysis of expected market conditions. The main objective in making a forecast is that it forces us to look at the future objectively. Companies that take note of the past should stay aware of the present and precisely analyze that information to see into the future.

Conducting a sales forecast will present your business with an evaluation of past and current sales levels and annual growth, and let you evaluate your company with industry norms. It will also help you establish your policies so that you easily can control your prices and operating costs to guarantee profits, and make you aware of minor problems before they become major problems.

Sales forecasting is a self-assessment tool for a company. You have to keep taking the pulse (sales forecast reports, graphs and analyses) of your company to know how healthy it is. It can make the difference between just surviving and being highly successful in business. It is a vital foundation of a company's budget. The future direction of the company may rest on the accuracy of your sales forecasting.

Implementation of an accurate sales forecasting process helps companies to enhance cash flow, know when and how much to buy, in-depth knowledge of customers and the products they order, the ability to plan for production and capacity, the ability to identify the pattern or trend of sales, determine the value of a business above the value of its current assets, ability to determine the expected return on investment (This can be very helpful if the company is trying to obtain financing from investors or other lending institutions) .

\subsection{Information needed to prepare a Sales Forecast}

Since the forecast mostly depends on your company's past sales, it is needed to know your dollar sales volume for many years before. To complete a comprehensive sales forecast, you also need to take into consideration all of the elements, both internal and external, that can affect sales.

Mathematically, it is possible to forecast sales with some accuracy. Realistically, however, this accuracy can be affected by external market and economic factors that are out of your control. Some external factors that can affect sales are: Seasonality of the business, Relative state of the economy, Direct and indirect competition, Political events, Styles or fashions, Consumer earnings, Population changes, Weather, and Productivity changes. 


\subsection{Forecasting accuracy measures}

There are several statistical methods available to evaluate forecast performance. Table 1 below lists the commonly used measures. Mean Absolute Percentage Error is the most widely used measure because of its statistical properties.

Mean Absolute Percentage Error method is used for measuring forecasting error in this article. The formula used to calculate mean squared error is:

$$
M A P E=\frac{1}{n} \sum_{i-1}^{n} 100 \frac{\left|A_{f}-F_{i}\right|}{A_{t}}
$$

\section{Data, Information and Knowledge}

Knowledge production is the most important value creating activity, not just for huge knowledge-based companies, but also for the society in general (Drucker, 1993; Stehr, 1994). Today, knowledge is called the key asset, the effective utilization, which determines success for the organization and knowledge management is the value generating process in organizations which generate value from their intellectual and knowledge- based assets (Meridith Levinson, 2003). First step to know about knowledge management is to know the distinction between different concepts of knowledge. There is an important difference between data, information, knowledge, and wisdom. Data is defined as a flow of events or activities captured by an organization's system that, by itself, is useful for transacting but not more than that. Data also has various definitions, mostly depending on the context of its use. For example, Information Science defined data as unprocessed information and other domains leave data as a representation of objective facts.

Data can be stored in databases, or fill a store. Data can be mined for useful information or we can extract data. We can look at the data or experience the uniformity of data entry.

To convert data to useful information, an organization must use its resources to organize data to categories which are understandable. For converting information into knowledge organization has to use more resources to find out patterns, rules, and contexts where the knowledge works. Eventually, wisdom can be the implementation of the knowledge to solve problems. In fact, wisdom is thought to be the answer to where, when, and how to implement knowledge. Figure 1 demonstrates DIKW linear chain.

\section{Tacit and explicit knowledge}

Nonaka \& Takeuchi $(1983,1995)$ classified Knowledge into explicit and tacit according to its complexity.

Michael Polanyi described the difference between these two kinds of knowledge in 1966 (Polanyi, M., The Tacit Dimension, Routledge \& Kegan Paul, 1966).

Explicit knowledge is knowledge that can be readily transmitted to others, expressed in formal language, codified and stored in specific media. One way to build a bridge between seekers and providers of knowledge is using electronic tools.

Tacit knowledge is knowledge that is transferred to another person difficultly through intangible factors as personal perspective, belief, instinct, and values. Tacit knowledge is mostly in form of verbal and personal rather than documented and codified knowledge which are considered as explicit knowledge.

\section{Knowledge Management}

Knowledge management is a managerial activity that develops transfers, transmits, stores and applies knowledge, when it provides real information for the members of the organization to react and make the right decisions, in order to reach organization's goals. KM is managing the corporation's knowledge through a systematically and organizationally specified process for acquiring, organizing, sustaining, applying, sharing and renewing both the tacit and explicit knowledge of employees to enhance organizational performance and create value (Allee (1997) Davenport (1998), Alavi and Leidner (2001)).

As keeping tacit knowledge within the organization is difficult, transforming tacit knowledge to explicit knowledge in order to preserve it is one of the most common activities of knowledge management. In other words, meanwhile tacit knowledge is very important for the organization. Its KM's goal to produce and store documented knowledge in order to use it in proper time. Thus documented knowledge within an organization can be assumed as a sign of knowledge management implementation whether consciously or unconsciously.

\section{Role of KM in forecasting}

Sales and new product forecasting should be identified as a need for any company's intelligence management 
process. Once this need is recognized it helps the company through the process of learning from business activities and guides it through the process of tracking and identifying the key elements.

This forecasting process should equate with the KM process. Thus the need for an efficient KM infra structure is highlighted, since the failure in the forecasting is not usually resulted from inefficient techniques but from inefficient KM systems. Hence the forecasting process is usually considered as a KM process, the intelligence taken through which supports the sales forecasting and provides key implications for its process.

Data, information and knowledge; each has an important role in the process of sales and new product forecasting within the realm of KM. data are usually used for sales forecasting, information for new product forecasting, and knowledge for improving satisfaction in the forecasting process (B. Kahn, E. Adams, journal of business forecasting winter 2000-2001). Recognizing these implications clarifies the necessity to address all these classes of intelligence in the forecasting process through the KM system.

\section{Strategies of exchanging intelligence}

Two strategies can be used in each transaction of knowledge. Knowledge can be exchanged by codification and personalization. When knowledge is exchanged by a communication-based strategy which can be verbally, telephone calls, or face-to-face meetings it can be called a personalization strategy.

But exchanging knowledge can be codified. Reports, faxes, forms and any documents can be a way to exchange codified knowledge. Both ways have been used in firms to run the flow of intelligence in the firm. But it seems that by growing managerial science, keeping knowledge codified is becoming more important.

Having discussed two strategies for exchanging knowledge and three types of intelligence, now it is possible to develop a framework for intelligence network. According to this classification intelligence networks can be in six categories as bellow:

1- Personalized data

2- Personalized information

3- Personalized knowledge

4- Codified data

5- Codified information

6- Codified knowledge

In a knowledge management point of view, codified knowledge is the most important part of this classification. Since the main objective of knowledge management is to transform knowledge to explicit form, if the usage rate of codified knowledge in an organization is high, then it can be considered as a high rate of use of KM.

\section{Objectives}

This research is conducted to study knowledge management in terms of an element of forecasting accuracy as a business tool. The objectives of this study are:

1- To determine relationship between knowledge management and forecasting

2- To measure level of influence of knowledge management on forecasting accuracy in Iran's food retail companies.

3- To suggest a procedure to have more accurate forecasts using knowledge management systems.

\section{Hypothesis}

The study hypnotized that knowledge, and in a more accurate view knowledge management, has a positive relation with forecasting accuracy.

H1: Using knowledge in sales forecasting procedure increases forecasting accuracy. (Decrease forecasting error)

$\mathrm{H} 2$ : Using codification of knowledge in sales forecasting procedure increases forecasting accuracy.

\section{Methodology}

This research is focused on Iranian food retailer companies which are greatly dependant on sales forecasting. Ten major food retailer companies were selected and average of ten managers in each company were asked through questionnaires. A total amount of 112 valid questionnaires have been collected. Managers were surveyed about mechanisms they used in meetings for sales forecasting in recent one year. Mechanisms categorized under 6 major categories including personalized data, personalized information, personalized 
knowledge, Codified data, Codified information, and Codified knowledge according to intelligence as discussed before.

\section{Research Sampling and Data Collection}

Data for this research was collected through questionnaires, which had 35 questions. The questionnaires consist of 6 parts, covering the areas such as demographics, awareness about KM, data, information, knowledge, and opinion about impact of KM on forecasting and suggestions. The respondents were to rate the statements on a 7point Likert scale. Both English and Persian versions of the questions were distributed.

\section{Theoretical Framework}

A conceptual framework was designed to demonstrate 6 different intelligence networks which can be used in food retailer companies for sales forecasting. The framework consists of two elements, Personalized and codified intelligence. Under each phases, three kinds of intelligence were categorized: data, information and knowledge.

Also, for demonstrating the impact of using knowledge on forecasting accuracy, a theoretical framework was developed. Using knowledge in sales forecasting procedure increases forecasting accuracy, while codification of knowledge helps to have even more accuracy.

\section{Data Analysis}

In this study, Statistical Package for Social Sciences (SPSS) has been used as the statistical analysis tool. Results of data collection and data analysis are presented.

\section{Results and Discussion}

Results from 7 companies show that using knowledge, as a sign of using KM in sales forecasting procedures has a significant impact on forecasting accuracy. Results also show that using codified knowledge is more effective than personal knowledge. In Figure 3 comparison among companies based on use of codified knowledge in their forecasting procedure is shown. Another comparison which is demonstrated in Figure 4 is based on the use of knowledge generally. This separation is to examine impact of using codified knowledge which can be considered as explicit knowledge. As shown in Table1 Company 2 which used codified knowledge in $40.25 \%$ of its forecasting procedures had a significantly accurate forecasting with MAPE of 5.2\%. Company 1 also had less than $10 \%$ error in sales forecasting using $32.6 \%$ codified knowledge in its forecasting. In contrast, Company 5 which used codified knowledge less than $10 \%$ and mostly used data in forecasting procedure faced a $43.2 \%$ error which is not reasonable.

Putting use of knowledge management in seven companies respectively and comparing MAPE obtained, it can be found that there is a relationship between these two. It is obvious that by increasing the use of codified knowledge in forecasting procedures MAPE falls down. Also using SPSS correlation between use of codified knowledge and MAPE is -0.875 , using Pearson correlation coefficient, and -0.786 using Spearman rho correlation coefficient, which is a significant negative relation. Results obtained from SPSS are shown in Table 2. This finding can prove second hypothesis that using codified knowledge in sales forecasting procedure can increase forecasting accuracy.

Testing first hypothesis relation between use of knowledge and MAPE is obvious in Figure 4. Using SPSS correlation between use of knowledge and MAPE is -0.881 , using Pearson correlation coefficient, and -0.893 using Spearman rho correlation coefficient, which both are significant negative relations at 0.01 levels. This can prove first hypothesis that using knowledge in sales forecasting procedure can also increase forecasting accuracy

\section{Conclusion}

The result suggests that the use of Knowledge management based system increase forecasting accuracy. But this paper aimed to evaluate effect of using knowledge management on forecasting accuracy in food retail companies in Iran. 7 companies have been chosen and effect of using knowledge, and codified knowledge, as a sign of using KM, on forecasting accuracy was measured. Results demonstrated a significant negative effect, which means using KM could decrease forecasting error. As a result it can be suggested to companies which have sales forecasting as a routine activity, shifting to use knowledge instead of data or information. Using codified knowledge seems to be more effective as companies can keep and document it. At the end it should be clarified that implementing knowledge management is not as simple as just using codified knowledge inside the company. It is a complicated and time consuming procedure which is a combination of Information technology and human resource issues. But this research can show using KM if be more functional and also use IT and HR issues can have even more effective results on forecasting accuracy, and as a result earn competitive advantage for the company. 


\section{References}

Daniel Chandran1 and Kavitha Raman. (2009). Awareness and Problems in Implementing Knowledge Management Systems in Medium Sized Business Organizations in Malaysia. J Soc Sci, 19(2): 155-161 (2009)

Hansen, Morten T., Nitin Nohria, and Thomas Tierney. (1999). What's Your Strategy for Managing Knowledge. Harvard Business Review, March-April, 1999, pp. 106-116.

Helander Nina, Hovila Hanna, Kukko Marianne, Virtanen Pasi. Knowledge Management Challenges in Renewal of R\&D Processes in Software Business.

Kahn, Kenneth B. (2000). Benchmarking New Product Forecasting Practices. IBF Research Report \#4. Flushing. NY: Institute of Business Forecasting, 2000.

Kenneth B. Kahn, \& Marjorie E. Adams. (2000). Sales forecasting as a knowledge management process. The journal of business forecasting, winter 2000-2001, p 19-22.

Levinson M. (2003). Knowledge management definition and solutions. [Online] Available: http://www.cio.com/article/40343/Knowledge_Management_Definition_and_Solutions

Maria Martensson. (2000). A critical review of knowledge management as a management tool. Journal of Knowledge Management, Volume 4. Number $\quad 3 . \quad 2000 . \quad$ pp. $204-216$. http://dx.doi.org/10.1108\%2F13673270010350002

Michael J. Baker (Ed.). (1999). Sales forecasting. International Thompson Business Press, p. 278-290.

Polanyi, M. (1966). The Tacit Dimension, Routledge \& Kegan Paul. http://dx.doi.org/10.2307/3149765

Ragna Seidler-de Alwis, Evi Hartmann. (2008). The use of tacit knowledge within innovative companies: knowledge management in innovative enterprises. Journal of Knowledge Management, Vol. 12 No. 12008 , pp. 133-147. http://dx.doi.org/10.1108/13673270810852449.

Smaros J., \& Hellstro“m M. (2004). Using the assortment forecasting method to enable sales force involvement in forecasting. International Journal of Physical Distribution \& Logistics Management, Vol. 34 No. 2, 2004, pp. 140-157. http://dx.doi.org/10.1108/09600030410526932,

Takeuchi, H., and Nonaka, I. (1986). The new product development game. Harvard Business Review, Vol. 64 No. 1, pp. 137-46.

Table 1. Common forecasting accuracy measures

\begin{tabular}{|l|l|l|}
\hline Technique & Abbrev & Measures \\
\hline Mean Squared Error & MSE & The average of squared errors over the sample period \\
\hline Mean Error & ME & $\begin{array}{l}\text { The average dollar amount or percentage points by which forecasts } \\
\text { differ from outcomes }\end{array}$ \\
\hline Mean Absolute Error & MAE & $\begin{array}{l}\text { The average of percentage errors by which forecasts differ from } \\
\text { outcomes }\end{array}$ \\
\hline $\begin{array}{l}\text { Mean Absolute } \\
\text { Percentage Error }\end{array}$ & MAPE & $\begin{array}{l}\text { The average of absolute percentage amount by which forecasts } \\
\text { differ from outcomes }\end{array}$ \\
\hline
\end{tabular}

Table 2. Data collected from seven companies

\begin{tabular}{|c|c|c|c|c|c|c|c|c|}
\hline \multirow{2}{*}{ Company } & \multirow{2}{*}{$\begin{array}{c}\text { Number of } \\
\text { managers }\end{array}$} & \multicolumn{2}{|c|}{ Data } & \multicolumn{2}{c|}{ Information } & \multicolumn{2}{c|}{ Knowledge } & MAPE \\
\cline { 3 - 8 } & Codified & Personalized & Codified & Personalized & Codified & Personalized & $(\%)$ \\
\hline C1 & 10 & 10.3 & 12.8 & 15.6 & 12.7 & 32.6 & 16 & 9.1 \\
C2 & 12 & 6.67 & 7.08 & 9.33 & 10 & 40.25 & 26.67 & 5.2 \\
C3 & 8 & 7.63 & 17.38 & 22.63 & 15 & 27.25 & 10.13 & 17.5 \\
C4 & 15 & 13.47 & 15.27 & 19.67 & 20.2 & 20.27 & 11.13 & 27.5 \\
C5 & 11 & 36.91 & 26.82 & 11.82 & 7 & 9.45 & 8 & 43.2 \\
C6 & 11 & 11.91 & 26.82 & 21.82 & 17 & 12.45 & 10 & 39 \\
C7 & 15 & 23.47 & 40.27 & 9.67 & 7.2 & 8.27 & 11.13 & 23.8 \\
\hline
\end{tabular}


Table 3. Correlations between variables

\begin{tabular}{|l|c|c|}
\hline Correlation coefficient & MAPE \& Use of codified knowledge & MAPE \& Use of knowledge \\
\hline Pearson coefficient & $-0.875 "$ & $-0.881^{4 "}$ \\
Significance(2-tailed) & 0.01 & 0.009 \\
\hline Spearman's rho & $-0.786^{\circ}$ & $-0.893^{\star "}$ \\
Significance(2-tailed) & 0.036 & 0.007 \\
\hline
\end{tabular}

* Correlation is significant at the 0.05 level (2-tailed).

**Correlation is significant at the 0.001 level (2-tailed).

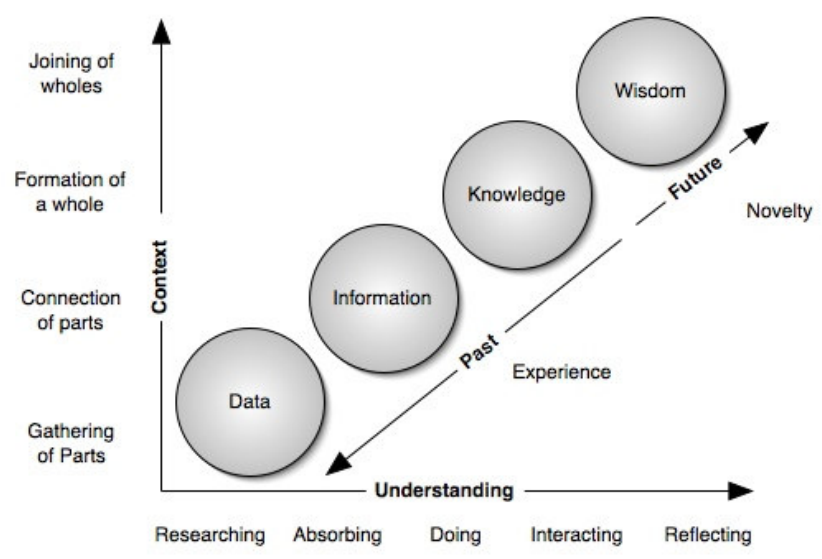

Figure 1. DIKW linear chain (Clark 2004)

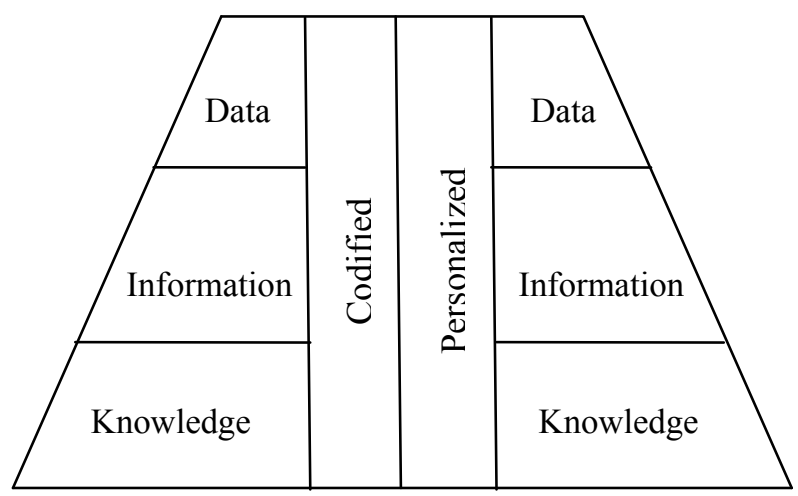

Figure 2. Intelligence network framework 


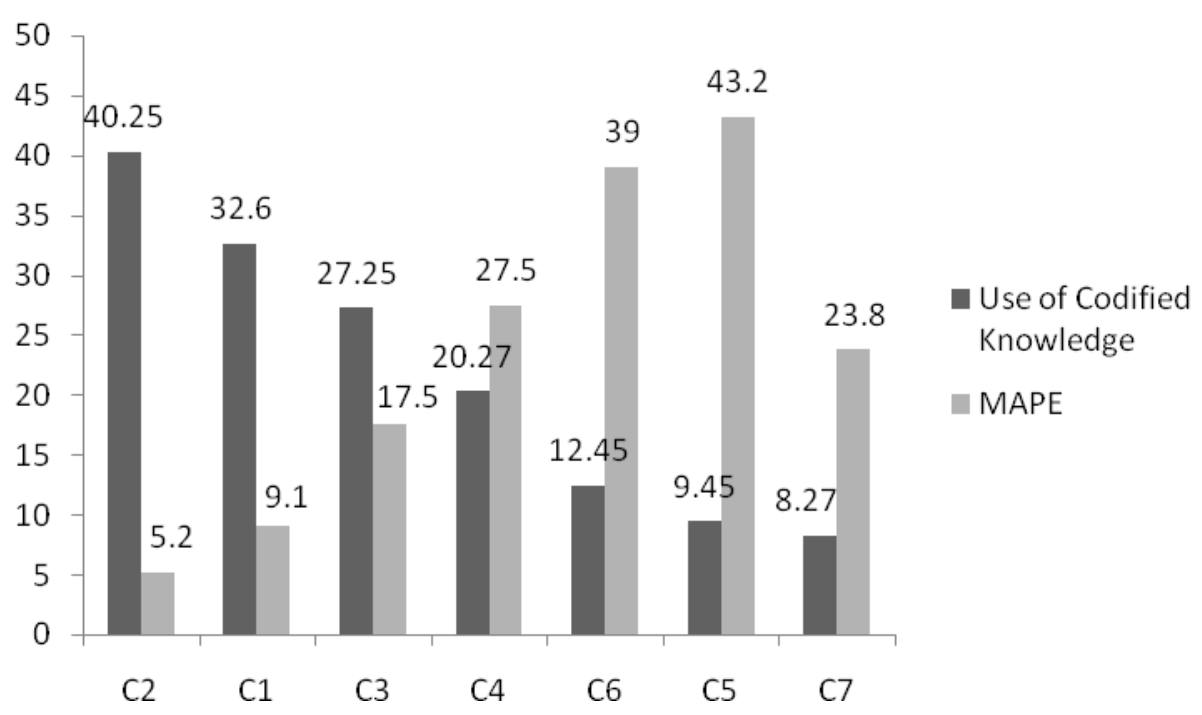

Figure 3. Impact of using codified knowledge on MAPE

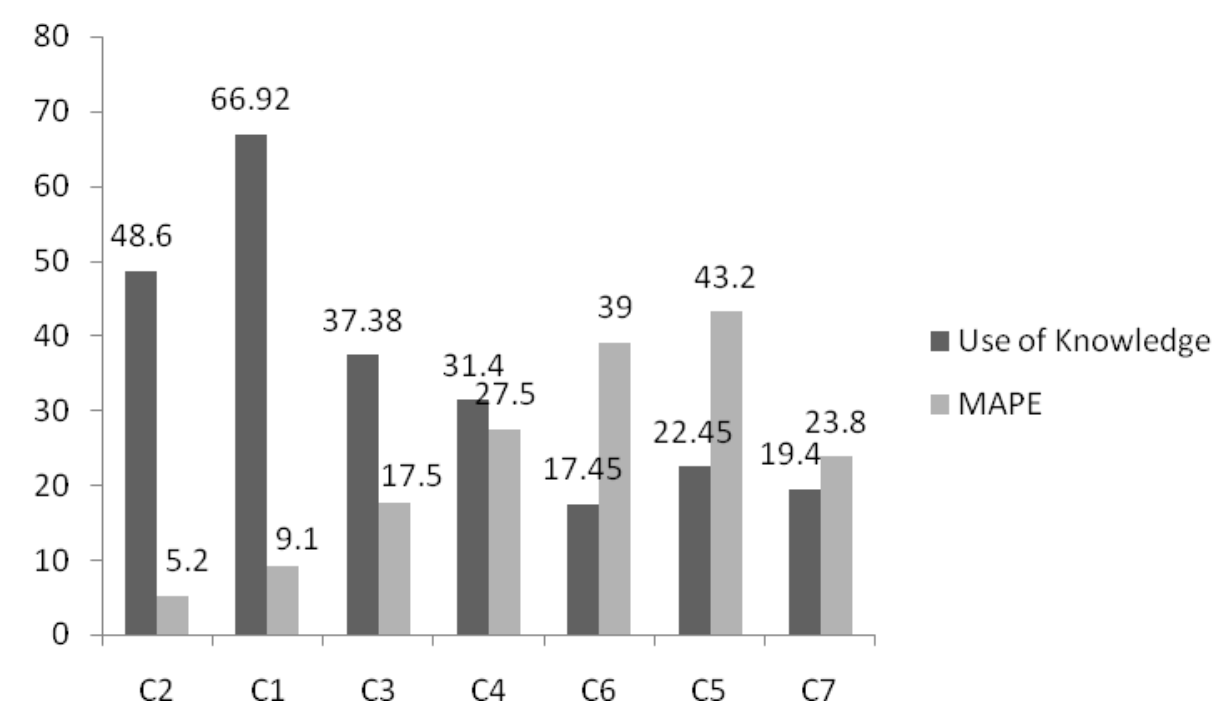

Figure 4. Impact of using knowledge on MAPE 